\title{
Censura y consignas en la prensa franquista. Algunos ejemplos de dirigismo informativo
}

\author{
Manuel Ruiz Romero \\ Grupo de Investigación en Estructura, Historia y Contenidos de la Comunicación \\ Universidad de Sevilla \\ Email del autor: mansusi@terra.es.
}

\section{RESUMEN}

De todos es sabido que la Ley de Prensa de Imprenta (1966) supuso un tímido intento aperturista en un régimen como el de Franco, el cual, por su misma génesis, estuvo caracterizado por un férreo control sobre medios, profesionales y mensajes informativos. Sin embargo, la denominada Ley Fraga persigue en la intención del régimen a la hora de poner límites a la apertura informativa y mantener altas dosis de intervensionismo en las políticas de comunicación. El presente artículo recupera algunos documentos inéditos que dan buena muestra de lo que afirmamos. El extinto Ministerio de Información y Turismo, a través de su Dirección General de Prensa y por medio de teletipos, mantenía una estrecha relación con las Delegaciones periféricas del mismo, de manera que, para el concreto caso sevillano pero también aplicables a otras provincias, hemos seleccionado un conjunto de ejemplos que nos ayudan a profundizar en las estrategias y actitudes de un importante periodo de la Historia de España.

\section{ABSTRACT}

It is very well known that the Press and Printing Law (1966) meant a slight opening attempt in Franc's regime, which, due to its own genesis, kept an iron hand over the mass media, its professionals and information. However, the so-called Fraga Law maintains the regim's attempt to confine the information opening and a very high interventionism in communicational policies. This article deals with some unpublished documents which prove what we state here. The former Ministry of Information and Tourism, through its Press Head Office and by means of teletypewriters kept closed links with its peripheral local offices. We have chosen a number of examples which contribute to deepen in the coercive attitudes and strategies which were put in practice during an important period of the Spanish History, both in Seville and in other provinces.

Palabras claves: Prensa/Franquismo/Censura/Intervencionismo/Consigna.

Key words: Press/Franquism/Censorship/Interventionism/Watch-word. 


\section{Franquismo y política de prensa: 1966 versus 1938.}

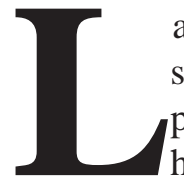
a censura es un complejo mundo que define a las dictaduras $y$, de forma sutil, sin nominarla de igual manera, condiciona las democracias. La prensa, como tal, significa igualmente un ente poliédrico sobre el que hay que matizar la relación entre profesionales de la comunicación y sus respectivas empresas, con sus estructuras periodísticas y el momento vivido ${ }^{2}$. Quizás por ello algunos autores se empeñan en matizar las definiciones que determinan el franquismo como dictatorial. Algunos hablan abiertamente de la "imposibilidad de calificar al régimen de Franco como totalitario" a partir de 1966 como año donde la Ley Fraga, aisladamente con respecto a la prensa, posibilitaría un "espíritu liberalizador (...) ya con un cierto respaldo legal". De ahí que se califique el sistema mediante perífrasis como de autoritario. ${ }^{3}$

No cabe duda que comparada con la normativa de la posguerra, el nuevo marco legal citado significaba un avance. Cuestión ésta, que sin embargo es matizada si observamos los necesarios progresos que deberían llegar en el Estado para recuperar las libertades democráticas. Está claro que no existía una libertad de prensa plena, pero admitiendo el espíritu liberalizador de 1966, es cierto que van a prodigarse posturas más independientes a las del Gobierno. Ello no resulta óbice para que el Ministerio busque orientar los contenidos de acuerdo con sus objetivos políticos, lo cual no sólo pretende asegurar la unidad ideológica de los medios y profesionales, sino que los escritos, particularmente en este caso, corren el riesgo de caer en un uniformismo reiterativo de claro prejuicio comercial. Ello quizás explicase, entendemos nosotros, el que salvo aisladas excepciones en determinadas provincias (el caso de Sevilla con ABC), se impusiera lo que pudiéramos denominar el monocultivo de la prensa escrita, en tanto el medio dominante en ámbito provincial suele ser de la Cadena de Prensa del Movimiento. ${ }^{4}$

La propia evolución institucional del régimen de Franco encontró propicio en esos instantes enterrar definitivamente una "caduca y anacrónica" Ley de Prensa de 1938, y sustituirla por otra “de cariz más liberal”. Más bien, añadimos nosotros, las nuevas exigencias internacionales del régimen hicieron más sutiles el control de la política informativa. Y ello, contrariamente a las posiciones que defiende Carlos Barrera al señalar -entendemos de forma pretenciosa-, que "entre

2 Conviene recordar que durante el periodo tardofranquista los Ministros de Información y Turismo fueron los siguientes sobre la fecha de nombramiento: Alfredo Sánchez Bella (29-X-1969), Fernando de Liñán y Zofio (12-VI-1973), Pío Cabanillas Gallas (4-1-1974), León Herrera Esteban (30-X-1974) y Adolfo MartínGamero. González (12-XII-1975).

3 Una visión general sobre los medios en el primer franquismo en: SEVILLANO CALERO, F., Propaganda y medios de comunicación en el franquismo (1036-1951), Alicante, Universidad, 1998, p. 377.

4 BARRERA DEL BARRIO, C., Periodismo y franquismo: de la censura a la apertura, Barcelona, Eiunsa, 1995, pag. 47. De este mismo autor: "La prensa como medio de oposición dentro del régimen franquista. 1966-1975", en AAVV, La oposición del régimen de Franco. Estado de la cuestión y metodología de la investigación, Vol. II, Madrid, UNED, 1990, p. 375. 
1962 y 1966 España vivió un tiempo de esperanza en lo relativo al aumento de la libertad de prensa"5. Y esto es justo lo que pretendemos poner en duda $\mathrm{y}$ demostrar con nuestros ejemplos referidos a la realidad sevillana, pero que muy bien podría extrapolarse, y de hecho así lo sería, al resto de provincias del Estado.

Ello no es óbice para entender que la madurez alcanzada por las empresas y medios de comunicación que nacen al amparo de la citada Ley Fraga, con diferentes ritmos y sensibilidades, se convierten durante el tardofranqusimo en un importantísimo rédito para la llegada de una transición sin extremismos. Permitió, entre otras cuestiones, que el ciudadano, una vez se inicia la Transición, estuviese más sensibilizado ante la necesidad democrática, por delante incluso de la incertidumbre política que se despejaba.

Pese a los indudables avances que la Ley de 1966 supone con respecto a la de 1938, fruto entre otras cuestiones, de la propia estabilización del régimen "en paz” tras la Guerra Civil, la elaboración de esta nueva Ley más bien pretende posibilitar la emisión de las opiniones que en el seno del franquismo emiten distintos segmentos de éste. Ésta y no otra interpretación más progresista, es la que parece desprenderse del circunloquio que implica el preámbulo de la citada Ley cuando alude a sus objetivos y a la nueva realidad social que da sentido al nacimiento de la norma: "La conciencia indudable de propiciar a dicha opinión \{pública\} cauces idóneos a través de los cuales sea posible canalizar debidamente las aspiraciones de todos los grupos sociales alrededor de las cuales gira la convivencia nacional". ${ }^{6}$

Sin embargo, como también se ha especulado, el quehacer cotidiano de la comunicación no se encuentra tan alejado en esta nueva década de lo que bien resume Justino Sinova: "El periodismo será concebido como una actividad de servicio al Estado; el periódico, como un instrumento de acción política; y el periodista, como un trabajador más de la Administración aunque su salario fuera pagado por una empresa privada".?

\section{De la censura a la consigna}

Podríamos resumir que la evolución de una Ley de Prensa a otra, significa la evolución de la censura a la consigna, sin que ello signifique que una u otra dejen de existir en cada uno de sus periodos. Sin embargo, sí entendemos que existe una actitud más prudente del sistema, fruto de la consolidación del régimen tras años de "reconciliación nacional". En cualquier caso, conviene recordar que estamos, con la Ley Fraga, ante una norma realizada contra la propia prensa, y

5 Loc. cit., pág. 88. Incluso el autor llega a definir esos años como periodo de "preparación para la libertad".

6 Preámbulo de la Ley 14/1966, de 18 de marzo, de Prensa e Imprenta (BOE, 67 - 19 de marzo de 1966).

7 SINOVA, J., La censura de Prensa durante el franquismo, Madrid, Espasa Calpe, 1989, p. 17. 
sobre la que la intervención del Estado se realiza en aras de una prolongación del poder del mismo. La carencia de espontaneidad es un factor que, como vamos a observar por los diferentes ejemplos que aportamos, afecta directamente al status deontológico de la profesión a la vez que ejerce un control ("verbal" podríamos decir, en función de cómo se trasmitían las consignas), sobre las estructuras periodísticas y trabajadores de la comunicación. La prensa, en este caso, no es más que un aparato más al servicio de los intereses del Estado, cuando no vehículo de propaganda, control de la opinión pública (o creación de otra afecta al poder), vigilancia y castigo. Las arbitrariedades de muchos de los ejemplos que comentamos nos induce a pensar en el intento de demostración de la tesis que da nombre a este epígrafe que, aún reducido el aspecto cuasi paramilitar de la comunicación, podríamos afirmar que nos encontramos ante una prensa al servicio del orden público. Quizás ello explique la estrecha vinculación del Ministerio de Información con tareas de mantenimiento de orden público y paz social.

Las referencias bibliográficas más concretas sobre lo que venimos afirmando la encontramos en las ya obras clásicas de Terrón y, sobre todo en Justino Sinova, por cuanto las investigaciones que este último realiza proceden de fondos del Archivo General de la Administración relacionados con la propia Dirección General de Prensa del Ministerio que analizamos ${ }^{8}$. Este último, precisamente, realiza la interesante apreciación: "Con la agobiante profusión de consignas, los periódicos fueron en la práctica incautados por el poder político, pues sus dueños naturales no podían elegir, sino entre aceptar el régimen de consignas y cumplir éstas a rajatabla o cerrar el periódico. Los amos efectivos de toda la Prensa fueron las autoridades, que en cada momento se ocuparon del control y la pusieron (...) a los pies del régimen". ${ }^{9}$

De esta forma podemos concluir que la Ley de Prensa de 1966 significa un periodo de evolución dentro del periodo franquista entre la llegada de la democracia y la Ley de 1938, en tanto conforma la crónica anunciada de una aspiración censora que nunca llega a cumplirse totalmente, sino que, muy al contrario, posibilitará un conjunto de situaciones que -como ya hemos expresado-, permite la llegada sociológica de la transición antes que tenga lugar la muerte del dictador $^{10}$. Con unas condiciones más relajadas a la inmediata finalización del conflicto

8 TERRÓN MONTERO, J., La prensa en España durante el régimen de Franco. Un intento de análisis político, Madrid, CIS, 1981. Entre sus páginas encontramos un interesante análisis del proceso de elaboración de la Ley de 1966.

9 SINOVA, J., La censura de Prensa durante el franquismo,... op. cit., p. 162. Especialmente este autor entre las páginas 123 a 160 de la citada obra, nos presenta una casuística cercana a la que desarrollamos en este artículo. Del mismo modo, nos reproduce las hojas de inspección de uso interno en el Ministerio, utilizadas no sólo sobre cabeceras y líneas editoriales, sino sobre profesionales (pág. 133).

10 RUIZ ROMERO, M., "La prensa de Andalucía durante la transición", en Ambitos. Revista Andaluza de Comunicación, (1), Sevilla, 1998, pp. 231 252. (ISSN 1139-1979). Reproducido también en la publicación electrónica Latina de Comunicación Social, (16), abril de 1999 (ISBN-1138-5820). (Disponible en http: / / www.ull.es/publicaciones/latina/a1999iab/100bruiz.htm) 
bélico producto de la intentona golpista, la norma de 1966 intentó más sutilmente convertir los medios en una continuación del poder, y en mucho casos, bien podemos afirmar que los medios fueron una prolongación del aparato de información ministerial al servicio de la causa de aquel Estado. Y defendemos esto, no sólo por cuanto el ejercicio de lo que entendemos como censura negativa, sino por una intencionada labor inspectora y policial efectuada sobre empresas, profesionales, contenidos y formatos comunicativos. Destinada, en definitiva, a controlar la aparición de una opinión pública diferente a la perseguida desde la dictadura. Al hilo del desarrollismo de los años sesenta, dicha labor se vuelve por obvias razones mucho más compleja que al finalizar el conflicto bélico, por lo que dicha estructura fuertemente centralizada, cuasi paralela a la de orden público adscrita al Ministerio de Gobernación, resulta en algunos instantes de una dificultad manifiesta a medida que la propia sociedad española supera la parca realidad de la posguerra. En este sentido, consignas y la propia censura se fueron adaptando a las nuevas circunstancias legales y sociales, prosiguiendo -en todo caso-, con las medidas de depuración de profesionales de la comunicación en la medida que una nueva generación se incorpora al ejercicio comunicativo.

\section{El fondo documental}

Cabe hacer constar igualmente que los fondos constituyen varias carpetas como resto de la documentación proveniente de lo que en su día fue la Delegación Provincial del Ministerio de Información y Turismo en Sevilla (c/ Trajano), sobre cuya existencia fuimos advertidos en su día por el Secretario General de la actual Delegación Provincial de la Consejería de Turismo y Deporte de la Junta de Andalucía. Se trata de unos dos mil documentos correspondientes a las comunicaciones internas emitidas entre la Dirección General de Prensa del citado Ministerio y la Delegación Provincial de Sevilla. Gran parte de ellas teletipos por ser un medio consolidado y rápido en la época. En la medida que vienen siendo estudiados, pasarán posteriormente a engrosar los fondos del Archivo Provincial de Sevilla como organismo competente de su custodia según corresponde por la Ley de Archivos. Del mismo modo, cabe señalar que los años que comprende dicha documentación se encuentran entre 1960 y 1973.

Pasemos a continuación a relacionar y analizar algunos de los ejemplos que hemos encontrado en dicha documentación, de la que consideramos el especial detalle con el que se explicitan dichas consignas o actuaciones, sin que ello deba significar necesariamente un orden de importancia en cuanto a su presentación.

\section{Las cortes del general Franco}

Nuestro primer caso se refiere a la intervención en las Cortes franquista de 1972 del procurador Gonzalo Rodríguez del Castillo. Fruto de su intervención, explicitada mediante texto cifrado y por lo tanto inteligible, tiene lugar desde los 
servicios centrales el envío de las siguientes medidas: «El Presidente de las Cortes, en su uso de sus derechos reglamentarios, ha prohibido que consten en Acta dichas manifestaciones. Con independencia de la posible repercusión penal que pueda producirse en relación con este asunto, debe advertirse a los directores que la difusión de los conceptos expresados citados por el citado procurador vulneran gravemente lo dispuesto en el artículo 20 de la Ley de Prensa en lo que se refiere al debido respeto a las instituciones y a las personas en la crítica de la acción política y administrativa, sin que en modo alguno el fuero que goza el señor procurador citado se extienda e exonera de responsabilidad al director de la publicación que las difunda». A la arbitrariedad de hacer que no conste en Acta de la sesión la citada, se une a continuación las instrucciones: "Los delegados deberán dar cuenta en la noche de hoy del texto del punto primero a los directores de los diarios y en la fecha más próxima a los directores de otras publicaciones periódicas de su provincia».

Incluso, se apunta que, los delegados provinciales ministeriales deben comunicar sus gestiones a Madrid el «haber traducido el cifrado y cumplimentado en la noche de hoy la instrucción recibida»: "por teletipo o por teléfono». Como argumento disuasorio e incentivo para el cumplimiento del deber, en la Circular de la Dirección General de la Prensa se recuerda que es «indispensable» el hecho de que en la misma noche sea cumplimentada la nota. "Ya que se trata de evitar, se apunta, (...)se tenga que buscar la respuesta de los delegados a horas inoportunas de la madrugada». Finaliza el teletipo con una repetición a modo de confirmación de la parte cifrada. ${ }^{11}$

\section{Los telegramas de Franco al Papa}

La identificación del Jefe del Estado como primer cristiano era una equivalencia especialmente cuidada por el sistema. Se ahí su preocupación cuando los medios no reflejaban obligatoriamente la noticia. Esta omisión -de la que desconocemos su intencionalidad manifiesta u oculta-, sucedió en el medio de la Iglesia en Sevilla, por lo que muy presumiblemente el Delegado hispalense comunicaría tal extremo al Director General de Prensa. Es muy probable que, a su vez, Madrid le insistiera en el asunto por lo que realizada las debidas gestiones se comunica de forma urgente el resultado de dichas gestiones: «Puesto al habla con el director del periódico El Correo de Andalucía don José María Javierre Ortas, manifiesta no haber habido intención en la omisión del telegrama del Jefe del Estado español a su santidad Pío EFE Pablo VI, habiendo prometido su publicación en el número correspondiente a mañana domingo». ${ }^{12}$

11 Copia de teletipo sin numerar, datado el 10-II-1972.

12 Copia de teletipo urgente $\left(n^{\circ} 5417\right)$. 


\section{El seguimiento a la vida cultural}

Como en todo proceso de comunicación la posibilidad de retroalimentación también existe. No faltan ejemplos de la información puntual que Sevilla ofrece en 1968 al Subdirector general de los Servicios Informativos sobre determinados hechos, y sobre lo que más preocupa: su trascendencia alrededor de los medios escritos. Tal es el caso de la visita a Sevilla de Rafael Calvo Serrer para impartir una conferencia en el Colegio Mayor Almonte "del Opus Dei» según consta la nota. El Delegado Provincial, Castro Villacanas remite los resultados del acto, que finalmente resultaría ser un coloquio una vez «hubo ciertos inconvenientes gubernativos, de carácter no formal». Recogiendo algunos párrafos de la entrevista efectuada por El Correo de Andalucía, presumiblemente la misma fecha en la que se remite la circular a las 21,40 horas del día 27 marzo de 1968, y «bajo el epígrafe vida cultural, con el título a dos columnas de entrada, en la parte superior: Coloquio de Calvo Serrer en el colegio». En él se informa de algunas de sus declaraciones: «En el terreno exclusivamente político, lo que hoy se lleva es la socialdemocracia, superadora de las concepciones típicas del comunismo, del socialismo y de la democracia». Interrogado por la fórmula de gobierno que adoptaría para la continuidad del actual régimen, Calvo señala que «lo más probable es el advenimiento de un rey. Ahora bien, esto no lleva implícito la adopción de la monarquía como sistema de gobierno: la venida del Rey está motivada por razones pragmáticas, porque no es viable la presencia de un militar en la Jefatura del Estado y por la estabilidad que supone la solución monárqui$c a »{ }^{13}$

\section{El funeral de Manuel Giménez Fernández}

La muerte del catedrático de Derecho e ilustre republicano es aprovechada por los disidentes de la dictadura para homenajearle con sus protestas ${ }^{14}$. Su Facultad había anunciado un funeral, y coincidiendo con los hechos se había convocado una asamblea «libre» en los jardines a la entrada al recinto. Según explica la nota enviada a Madrid, una vez el sacerdote se disponía a celebrar la misa ha comunicado que, por orden del Rector y ante el intento de aprovechar los funerales para "otros fines", quedaban suspendidos hasta nueva fecha, "cuando las cosas estuviesen más tranquilas». Instante en el que los asistentes que había

13 Teletipo (s/nº $)$ del Delegado al Subdirector General de Servicios Informativos fechado el 27-III-1968 a las 21,40 horas.

14 Un aspecto poco conocido en la biografía de este personaje hispalense e inédito en los estudios que se han dedicado a su persona es su decidida y crucial participación en el proceso autonómico de Andalucía durante la Segunda República. Cfr. al respecto: DIAZ ARRIAZA, J. y RUIZ ROMERO, M., El proceso autonómico de Andalucía durante la II República, Sevilla, Fundación Blas Infante, 1991; así como HIJANO DEL RIO, M. y RUIZ ROMERO, M., El Ideal Andaluz en la II República. La Asamblea Regional Andaluza de 1933, Sevilla, Fundación Blas Infante, 1995. 
a la entrada de la capilla de la Universidad la abandonaron y a la salida los estudiantes, "que no habían entrado en su mayoría comenzaron a gritar: Libertad, libertad"15. Igualmente, un día antes los estudiantes que se habían encerrado en el Aula Magna de Derecho fueron desalojados por la policía que penetró en el recinto de la Universidad a petición del Rector. Se habla -continúa recogiendo la nota-, de una "posible clausura temporal de la Universidad ante la persistencia de la actitud rebelde". ${ }^{16}$

\section{La actividad estudiantil}

Los sucesos estudiantiles, entre otros, son ampliamente valorados y estrechamente perseguidos. Así nos encontramos con la información que desde Sevilla se remite a Madrid, en la que se alude a la nota aparecida en El Correo de Andalucía el 13 de enero de 1967, realizada por su corresponsal J. Oneto Revuelta, enmarcada en los siguientes titulares: «La Facultad de Económicas de Madrid fue cerrada sin base legal», «los estudiantes creen que no existía una situación de urgencia que aconsejase la sanción», "fruto de esta medida son los nuevos choques entre universitarios y policía». Entre otras cuestiones, el diario sevillano concluye su información -se sigue diciendo-, con las siguientes palabras: «Muchos estudiantes muestran su extrañeza ante una medida, tomada sin acuerdo del Consejo de Ministros, y cuya responsabilidad la ha asumido el Ministro de Educación y Ciencia». Por último, la información en prensa que se remite a la Subdirección General recogen algunos hechos acaecidos en Sevilla, entre los que se encuentran las valoraciones jurídicas sobre la ilegalidad de la medida publicada a su vez por el diario Madrid. Todos ellos, se dice, estiman que la «autoorganización es un derecho inalienable de todos los universitarios, y cuyo proceso debe consolidarse a la mayor brevedad. Es decir, que los propios estudiantes creen su organización sindical, único medio de conseguir la reforma democrática de la universidad». ${ }^{17}$

\section{El control a la Iglesia comprometida}

Algunos sectores de la Iglesia comienzan a ser especialmente vigilados de cerca por el régimen, y en este caso, tenemos noticias de un registro en una residencia de jesuitas cuestión que, como es de suponer, no trasciende a medio alguno. «El Gobernador Civil de la provincia ha informado esta mañana al Delegado Provincial que suscribe -Castro Villacanas-, que ha obtenido autorización del ordinario para que la policía gubernativa lleve a cabo un registro en la

15 Teletipo ( $\mathrm{n}^{\circ}$ 1352) del Delegado al Director General de Prensa fechado el 5-III-1968 a las 12,55 horas.

16 Teletipo ( $n^{\circ}$ 1342) del Delegado al Director General de Prensa fechado el 4-III-1968 a las 18,10 horas.

17 Teletipo ( ${ }^{\circ}$ 220) del Delegado al Subdirector General de Servicios Informativos fechado el 13-I-1967 a las 11,35 horas. 
residencia de los padres jesuitas de esta capital». Le preocupaba encontrar una relación entre la organización juvenil «vanguardia obrera», controlada, "como es sabido”, se dice, "por la Compañía de Jesús con la organización de actos de significación subversiva que, según parece, se preparan para el próximo día 30”. Ello induce a pensar, se sigue comunicando, la aparición por diferentes puntos de la ciudad de pintadas donde se lee: "treinta de abril comisiones obreras". Es más, según apunta la misma nota a modo de justificación, se tiene noticias de las acciones que pretende montar la aludida entidad para el día 24 ante la caseta del Círculo de Labradores en la misma Feria de abril, «con pancartas y gritos contra el lujo, gastos excesivos, etc». ${ }^{18}$

\section{El primero de mayo}

El carácter sindical de la festividad no escapa al control de los elementos disidentes del régimen, así como a la posibilidad de que en diferentes púlpitos se exaltara más de lo acusado el carácter reivindicativo de las condiciones laborales y de vida del sector obrero. Por ello, los delegados debían manifestar, con la mayor urgencia, a la Subdirección General «si el prelado de la diócesis respectiva ha hecho pública alguna pastoral el pasado día 1 de mayo festividad de San José Artesano». (Puede observarse la divertida perífrasis para no denominar al santo como obrero, cuestión es de suponer más propia de la jerga subversiva del momento). Caso afirmativo -se afirma-, se solicita remitir, «con la mayor urgencia, el texto impreso de la misma, o indicar si algún periódico de la diócesis lo ha insertado de manera textual o bien «hubiera recogido solamente un extracto». Supuesto este último en el que «se hará de todas maneras necesario recibir texto íntegro». ${ }^{19}$

Posteriormente, y a modo de balance sobre los sucesos que hayan podido acontecer, un nuevo Boletín a los Delegados reclama, como complemento a lo manifestado el día 5 (en realidad seis) prestar su atención a la publicación «por los obispos de las diócesis respectivas de cartas pastorales homilías u otros escritos que lleven su firma». Con la intención de que, tan pronto se tenga conciencia del texto «por su publicación diocesana o en prensa» (esto último en clave indescifrable) deberán dar cuenta a la Dirección General. ${ }^{20}$

18 Copia de teletipo ( o $^{\circ}$ 2217) del Delegado al Director General de Prensa fechado el 19-IV-1968 a las 1,30 horas. El primer intento de abordar el papel de la Iglesia en el compromiso autonomista lo encontramos en: DEL RÍO MARTÍN, Mons. Juan, "El papel de la Iglesia en la autonomía andaluza", ponencia mecanografiada en el VI Curso de Otoño de la Universidad de Cádiz: Andalucía 25 años después: de la transición a la autonomía (1975-2000), Jerez, 2001 (en prensa).

19 Teletipo con Boletín Informativo para los Delegados ( $\left.\mathrm{n}^{\mathrm{o}} 105\right)$, registro de entrada $\mathrm{n}^{\mathrm{o}} 2155$ de fecha 6-V1971. La contestación es rotunda desde la Administración periférica del Estado: «El Cardenal Arzobispo de la diócesis no ha publicado ninguna pastoral con motivo del primero de mayo». Teletipo a Madrid de 6 de mayo de 1971, núm. 1914.

20 Una hoja en tamaño holandesa grapada al teletipo nos hace presuponer que pudiese tratarse del contenido descifrado del mensaje en clave: "Por los obispos de las diócesis respectivas de cartas pastorales homilías u otros escritos que lleven su firma. Por su publicación diocesana o en prensa”. 
Dentro de esta política de seguimiento del 1 de mayo se inscribe también la comunicación de los textos de los panfletos encontrados, alrededor de la jornada de lucha convocada por Comisiones Obreras desde el 30 de abril al 1 de mayo. Es más, remite el Director General Fernández Sordo a las delegaciones su interés por «prevenir la posibilidad de que las delegaciones provinciales autoricen, en trámite de consulta voluntaria textos o comentarios que hubieran sido sancionados con anterioridad por la Dirección General de Prensa o que estuviera en periodo de instrucción del expediente". «Dicha posibilidad - aclara la nota-, es perfectamente admisible, habida cuenta que la decisión en lo que atañe a las circunstancias voluntarias, es una actividad discrecional del Delegado y el criterio de aprobación o denegación puede ser muy variable en razón de circunstancias que no siempre se relacionan con la posible infracción de la ley de prensa». Como principio se recomienda tener un criterio «restrictivo, aún cuando el texto consultado no suponga infracción administrativa», por lo que debe procurarse, que la conformidad no se interprete como "conformidad de la administración con el contenido o las tesis del comentario». Así, para facilitar una mayor coordinación se comunicará a través del Boletín de Delegados, los expedientes administrativos que se instruyan, "con indicación del periódico de que se trata, título del artículo o comentario y nombre o firma del autor». ${ }^{21}$

De otra parte, cabe señalar también que el Delegado Provincial por su parte en el uso de sus "funciones" alerta a los servicios centrales del Ministerio de la nota que pretende publicar El Correo de Andalucía en este caso, durante la edición del 28 de junio de 1971. Se trata de una situación en donde las declaraciones que desconocemos de un alto responsable del Gobierno en respuesta a la creciente preocupación e implicación social de algunos sectores de la Iglesia, por extensión y hábilmente interpretada por los críticos al sistema, se vuelve contra el propio régimen y sus vinculaciones cómplices con parte de la autoridad eclesial: «A la vista de las declaraciones del Sr. Ministro de Justicia y del modo como han sido resaltadas por numerosos medios de difusión algunas de sus frases, de las cuales se deducen consecuencias que resultan difamatorias para todo el clero y los militares cristianos, cosa que implica una acusación inaceptable y, sobre todo, provoca la deformación de la opinión y mente del pueblo, 43 sacerdotes presentes en la terminación de la Asamblea Diocesana Sacerdotal, han rogado al Sr. Obispo que se dirija -como así lo ha hecho-, al Sr. Cardenal Primado, Presidente de la Conferencia Episcopal, haciéndole constar su repulsa de tales manifestaciones y solicitando que en la Asamblea conjunta de obispos y sacerdotes se aborde

21 Teletipo con registro de entrada 11 de mayo de 1971 ( $\left.\mathrm{n}^{\circ} 2256\right)$ a todos los Delegado por el Subdirector General de Servicios Informativos, Fernández Soto. 
decididamente este problema». En consecuencia, la Delegación advierte que parece que la misma nota se pretende sea publicada en los medios de Madrid. ${ }^{22}$

Es de imaginar que después de las recomendaciones que se recibiese de la autoridad central, y tras las oportunas presiones al medio, una hora y cuarto después de enviado el primer teletipo, un segundo dirigido a Gonzalo Rodríguez del Castillo explicita el texto que se publicaría al día siguiente en dicho medio y en sustitución de la anterior: «La Asamblea Sacerdotal de Huelva.- Recusan las declaraciones del Ministro de Justicia.- Al término de la asamblea conjunta celebrada en la diócesis de Huelva, los cuarenta y tres sacerdotes que asistieron a la clausura redactaron un anota para la prensa y la radio en la que recusan las recientes declaraciones del Sr. Ministro de Justicia. Esta nota fue leída el domingo pasado en los púlpitos de numerosas iglesias de la diócesis. En la nota se subraya que las declaraciones del Sr. Ministro y especialmente el modo como han sido resaltadas algunas de sus frases en los medios de difusión, podrían crear estado de inquietud por parte de los fieles hacia el clero y los militantes cristianos, ya que contienen matices poco claros sobre ideología y la conducta de los sacerdotes. Por lo cual los cuarenta y tres sacerdotes presentes en la clausura de la Asamblea Diocesana sacerdotal, rogaron al Sr. Obispo de Huelva que se dirigiera, como así hizo, al Sr. Cardenal Primado, Presidente de la Confederación Episcopal, expresándole el deseo de que en a Asamblea conjunta Nacional de Obispos y sacerdotes se procure esclarecer debidamente estas cuestiones». La nota había sido matizada, convirtiéndola como podemos apreciar, en una reclamación de mayor mesura y prudencia en las declaraciones públicas gubernamentales. Habiéndose eliminado en consecuencia la dimensión de alarma social y repulsa que contenía la primera nota. ${ }^{23}$

En un orden semejante vamos a documentar distintas alertas que a modo de advertencia se realizan desde la Dirección General. Así, la comunicación, aludiendo a que "alguna provincia ha advertido que en fecha inmediata intentan celebrar ruedas de prensa», obviamente de elementos contrarios al régimen. Determina realizar orientaciones encaminadas a: evitar su anuncio o su transmisión por agencias nacionales, prohibir publicación en prensa local, de no ser factible esto último factible, cuidarán que la noticia se reduzca lo más posible y se limite a exponer en abstracto el hecho de la rueda de prensa y su contenido. Por lo general, los Delegados acusarán recibo de este boletín extraordinario, así como de haberlo descifrado normalmente. ${ }^{24}$

22 Copia de teletipo urgente ( $n^{\circ} 299$ ) del Delegado al Subdirector General de Servicios Informativos fechado el $28-V I-1971$ a las 19,15 horas.

23 Copia de teletipo "muy urgente" ( $\mathrm{n}^{\circ}$ 300) del Delegado al Subdirector General de Servicios Informativos fechado el 28-VI-1971 a las 20,45 horas.

24 Incluso, el control llega a tal extremo que, según constan en otros ejemplos de la documentación que hemos manejado, las homilías con motivo de las jornadas contra el hambre son transcritas íntegramente a la Dirección general por si fueran constitutivas de delito, y una vez el hambre es relacionado con la problemática socio económica de la Sevilla y Andalucía de entonces. 


\section{Protegiendo el turismo}

A nadie escapa la importancia del turismo para el régimen, no sólo por cuanto significa una esencial fuente de entrada de divisas para el mismo régimen, sino por cuanto forma parte de una cierta nueva imagen de la dictadura en escenarios internacionales. España se jugaba mucho en esos momentos con este tema, de ahí las recomendaciones a las delegaciones para evitar cierto alarmismo ante determinadas noticias de países vecinos, máxime si por ese mes en cuestión, no son pocos los magrebíes que cruzan el espacio geográfico peninsular: "Ante las informaciones de algún periódico de Madrid donde se señalaba la existencia de algunos casos de cólera en Marruecos, señalo a V.I. que advierta a los medios informativos locales que no publiquen ninguna noticia sobre el tema, por cuanto puede crearse un clima alarmista que perjudicaría notablemente a nuestro turismo, sin causa justificada». La comunicación al Director General de Prensa precisa que ya el Ministro de Sanidad ha «retirado» unas declaraciones por considerar injustificada la alarma. ${ }^{25}$

\section{Exaltación de los episodios nacionales}

La fecha de la conmemoración de una histórica batalla es también motivo de utilización por parte del régimen, a la hora de sensibilizar a la ciudadanía de valores tales como el papel al que estaba llamado a jugar España a la hora de proteger Occidente y la civilización cristiana. El recurso a determinados hitos históricos hace que nos encontremos ante una buena prueba de cómo el nacionalismo español ha sabido utilizar hábilmente para provecho y perpetuación de su ideología, a determinadas fechas en pos de su propio beneficio. ¿Quien dijo que la historia es neutral o que la manipulaban en exclusiva los llamados nacionalismos periféricos?. Así, ante la proximidad de la fecha de la conmemoración de la "histórica batalla de Lepanto", de orden del Director General se informa a las delegaciones en los siguientes términos: La fecha es considerada «objeto de publicidad de interés general» a efectos de los «trabajos» que puedan ver la luz sobre la efemérides, amén de los que ya enviará a sus clientes -se dice-, la agencia gubernamental Efe. Según afirma la comunicación, los espacios que ocupen las inserciones «serán facturadas estrictamente en base a las tarifas de publicidad vigentes en cada periódico"; remitiéndose a «fecha inmediata» sobre la forma de liquidar a las empresas periodísticas esta campaña. Obviamente corre a cargo del aparato del Estado este tipo de promociones de la sensibilización ciudadana. Por todo ello, se ruega que a la mayor brevedad tomen contacto los Delegados con los diarios de su demarcación dada la proximidad de la fecha. No obstante, se exceptúa de esta consideración todo lo que sean informaciones puramente perio-

25 Teletipo con registro de entrada 3 de julio de 1971 ( $\left.\mathrm{n}^{\mathrm{o}} 3235\right)$ a todos los Delegado por el Subdirector General de Servicios Informativos, Manuel Ortiz. 
dísticas que los medios puedan insertar sobre los actos públicos que tengan lugar por dicho motivo. «Inexcusable y necesariamente» se apunta finalmente, "según orden reiterada por el Ilmo. Sr. Director (...) esta comunicación de los Delegados Provinciales con los señores gerentes o administradores se realizara en forma oral y nunca escrita» (subrayado nuestro). ${ }^{26}$

\section{La importancia de la política internacional.}

El tema que nos ocupa ahora fue clasificado como «materia reservada». En la misma línea de comunicación desde la Administración Central del Estado hacia las dependencias provinciales, da cuenta de las intenciones efectuada al día de la fecha por el Ministro de Asuntos Exteriores: «El Estado presente de las relaciones diplomáticas entre España y la República de Guinea Ecuatorial, y las especiales circunstancias en que se pueden desenvolver en el futuro las mismas, en caso de previsible incidencia de noticias o comentarios desfavorables en los medios informativos españoles con respecto al Presidente Macias o al Gobierno Guineano, aconsejan en opinión del Sr. Embajador de la nación de Santa Isabel la declaración de materia reservada». ${ }^{27}$

En consecuencia, a partir del día de la fecha y por el plazo de seis meses, todas las informaciones son declaradas «materias clasificada» con la calificación de «reservada». Para ello se invita a un estrecho seguimiento de cuanto aparezca en los medios, o alteración en el sentido apuntado que se produzca en la universidad, fábricas o espacios públicos. Se ruega en esta misma línea, que los partes que se eleven a Madrid sean lo suficientemente concisos «para facilitar la reproducción y estudios». A los mismos, el delegado deberá añadir siempre al final alguna de estas indicaciones: a) si no procede realizar acción alguna; b) lo que el Delegado haya hecho o se proponga a hacer sobre el caso y c) lo que, sólo por exceder de sus facultades, deba realizar la Dirección General de prensa u otro organismo. ${ }^{28}$

En este mismo sentido, documentamos una nueva circular desde Madrid recuerda a los delegados el hecho de que continúa "en pleno vigor la reserva informativa amparada en la Ley de Secretos Oficiales” dispuesta en su día por la Presidencia del Gobierno en relación al Sahara español. "Como quiera que hay noticias procedentes de Naciones Unidad y Rabat-recoge la nota-, parece opor-

26 Teletipo con registro de entrada 3 de octubre de 1971 ( $\mathrm{n}^{\circ}$ 4.666) a todos los Delegados por el Subdirector General de Servicios Informativos Manuel Ortiz. En el teletipo aludido se encuentra anotado a mano el siguiente texto que confirma el curso de la orden: "Comunicado a Celestino, Joaquín Carlos y Requena". En referencia directa a los directores de la prensa local hispalense de la época.

27 Según se anota en el texto en función de la Ley 9/1968, de 5 de abril sobre secretos oficiales.

28 Copia de teletipo circular desde Madrid a los Delegados suscrita por Esteban de la Puente en calidad de Subdirector General de Régimen Jurídico de las empresas (es de entender de medios del Estado), registro de entrada $n^{\circ} 863$ de 5 de febrero de 1972. 
tuno recordar la mencionada condición”. Con seguridad, este secretismo pudiera explicar la sorpresa de que en los albores de nuestra Transición aparezca inesperadamente el interés alauita por dicho territorio, más tarde traducido en marcha verde. ${ }^{29}$

\section{Avisos sobre medios expedientados}

Pese a la intensidad de los recursos censores, la complejidad de las estructuras e iniciativas periodísticas hacen que las dificultades para el ejercicio de ese control institucional contra la libertad de expresión y prensa sea cada vez más dificultoso. Respondiendo a este motivo, es presumible que éste fuese el motivo por el que desde el aludido Ministerio se procediera a comunicar a las delegaciones las infracciones, no sólo con un interés informativo y ejemplarizante, sino para controlar la posible distribución en distintos puntos del Estado de dichas cabeceras, o bien la aparición del mismo texto en otros tabloides. Así, una nueva circular del año 1972 informa de lo siguiente: "Han sido acordadas las iniciaciones de expedientes administrativos a las publicaciones que a continuación se relacionan por la publicación de los artículos o testos periodísticos que también se mencionan". Los títulos de los artículos y la pluralidad de los medios hablan por si solos:

- Diario Primera Página de Alicante, por insertar en el número del día 2 de febrero de 1972 la entrevista con Emilio Gutiérrez Caba, firmada por Vicente Calvo Baguera.

- Revista Vida Nueva de Madrid, por difundir en el número 818 del 5 de febrero de 1972 el artículo titulado «Año nuevo mito nuevo. La cuesta de enero», cuyo autor es Eduardo Ciervo.

- Revista Mundo Social de Madrid, por publicar en el número 195 correspondiente al 15 de enero de 1972, el artículo «La universidad. Un mediador de la sociedad española», firmado por José María Mohedano Fuertes.

- Revista Gaeta universitaria, de Madrid, por difundir en el número 153 de enero de 1972 el trabajo periodístico titulado «Entrevista con Raúl Morodo: el país tiene necesidad imperativa de la democracia», firmado por Miguel Plantón.

- Diario Sol de España de Málaga, por publicar en el núm. 1477 de 10 de febrero de 1972, la información titulada «52 sacerdotes apoyan a los obreros de CITESA».

- Semanario Destino de Barcelona, por publicar en el número 1729 de 5 de febrero de 1972, el artículo titulado «La política a 621 kilómetros de Madrid» del que es autor Pablo de Columba.

29 Copia de circular desde Madrid a los Delegados suscrita por Esteban de la Puente en calidad de Subdirector General de Régimen Jurídico de las empresas (es de entender de medios del Estado), registro de entrada $\mathrm{n}^{\circ}$ 3426, de 15 de julio de 1974 . 
- Revista Asturias Semanal, de Oviedo, por difundir en el número 143 de 19 de febrero de 1972, la información titulada «Cartas de los estudiantes» que firma un grupo de estudiantes de la Facultad.

- Revista Cosmopolis de Madrid, por insertar en el número 33, correspondiente a los meses de enero-febrero de 1972, el artículo titulado «Una lección de Historia: el nacional catolicismo» del que es autor Moisés Pérez Coterillo. ${ }^{30}$

\section{La realidad a través de la prensa}

Puede resultar paradójico, pero como vamos a observar en algunos casos las informaciones aparecidas en los medios sirven a los poderes de la época de alerta. Este es el caso de una información aparecida en el diario El Correo de Andalucía, (núm. 31.583 correspondiente al 15 de marzo de 1972, en la pag. 8, sección: mundo laboral- según se dice en el teletipo), se difundió la noticia relativa a Sevilla y los Astilleros Españoles S.A. (Elcano), dando cuenta de que en los mismos se habían producido un paro masivo en solidaridad con las víctimas de la «Bazán». Por todo ello al Delegado se le «interesa» desde Madrid para que solicite informe al Gobernador Civil sobre la veracidad o no de la misa, indicando que el texto será utilizado «como base y fundamento del correspondiente expediente administrativo para la exigencia de la oportuna responsabilidad al director de El Correo de Andalucía». ${ }^{31}$

\section{El affaire Redondela}

El entonces Ministro Pío Cabanillas no estaba dispuesto a consentir que la prensa aireara un escándalo donde estaba implicado el propio hermano -Nicolás-, de Franco ${ }^{32}$. Así, presumimos que alertado por consignas emanadas de los servicios centrales del Ministerio, el delegado hispalense informa al Director General de Prensa de la existencia de un artículo bajo el título: «Otro affaire acitero: Redondela? cuándo habrá una luz clara”, editado en la pág. 3 de la revista Campo correspondiente a mayo del año en curso (3 junio de 1972, núm. 2626). Según se comenta mientras transcribe la integridad de su contenido, se trata de una publicación mensual con carácter agropecuario editada en Sevilla desde 1942. Su

30 Copia n $^{\circ} 60$ de 13 de marzo de 1972 enviada desde el Ministerio en Madrid a los Delegados provinciales.

31 Los referidos sucesos de Bazán a los que sugiere el texto se trata del fallecimiento de dos obreros de esta factoría naval en la coruñesa zona de El Ferrol del Caudillo, en enfrentamientos con la policía reivindicando mejoras laborales. Uno de los fallecidos era afiliado a Falange Española y de la JONS. La existencia de numerosas manifestaciones, paros, pintadas y panfletos sobre estos sucesos son enviadas como información a los servicios centrales. Teletipo al Delegado de Sevilla de fecha 13 de abril de 1972 registro de entrada 2186.

32 En concreto, el nombre del caso proviene de una empresa dedicada al refino y almacenamiento de aceites, REACE, en la que el hermano poseía importantes intereses. Este mismo año de 1972 se echaron en falta cuatro millones de litros de aceite de oliva. El curso de la investigación se desarrolló entre muertes en extrañas circunstancias. Finalmente, durante el juicio el defensor de uno de los acusados aireó al nombre de Nicolás y eso le costaría el cargo al propio Ministro Cabanillas. 
director por estas fechas (1970-1977) es José Antonio Garmendia Gil, siéndolo anteriormente Joaquín Carlos López Lozano.

Según señala el citado texto se "ha producido la desaparición de 4.052 toneladas métricas de aceite de oliva de los depósitos de la estación de gallega de Reace". Se cita también a personas supuestamente beneficiadas económicamente de esta desaparición, depositadas por la Comisaría de Abastecimiento y Transportes, toda vez eran excedente adquiridos en régimen de producción. La cantidad total del fraude asciende a 200 millones de pesetas, ante lo cual se reclama actúe la justicia por medio de un juez especial, y no se proceda al «stop secret» (sic) como ha sucedido con anterioridad en un caso de adulteración de aceites en la ciudad de Barcelona. Por ultimo, el artículo sentencia: «es hora que esa tradición fraudulenta con el aceite en nuestros días tenga serio escarmiento para ejemplo de todos».33

No debió de gustar la denuncia y la sugerencia cuando, el delegado toma la iniciativa, $\mathrm{y}$ «a su juicio», sugiere que se debe "abrir expediente al director de la citada revista por el contenido de los trabajos». ${ }^{34}$

\section{Control sobre el mundo de la cultura}

Una nueva circular pone de manifiesto la comunicación que el diario ABC dirige a la Delegación para cuya difusión le fue facilitado un texto cuyo contenido se transcribe. En el mismo, y dentro del Colegio Universitario Ramón y Cajal, se afirma que va a tener lugar un ciclo de conferencias durante los días 12 al 16 con motivo del I Centenario de la I República. El Delegado ministerial indicó la conveniencia que dicho texto no se publicase hasta que no exista la preceptiva autorización gubernamental. Extremo sobre el que, tras ponerse al habla con el Gobierno Civil, se afirma contar con el beneplácito del Rector de la Universidad, cuestión se aclara "que hasta este momento no se ha podido comprobar». Sin embargo, la comunicación a los servicios centrales del Ministerio se aclara que dichas conferencias han sido publicadas ese mismo día en El Correo de Andalucía «sin especial destaque», bajo título «vida cultural» y entre otras conferencias con «carácter normal». Es de imaginar esa normalidad en qué consistía y qué significaba realmente. Máxime cuando la palabra de todo un Rector debía de ser comprobada. Moraleja: La historia como arma subversiva. ${ }^{35}$

33 Circular núm. 2626 del día 3 de junio de 1973 al Director General de Prensa.

34 Circular núm. 26486 del día 6 de junio de 1973 al Director General de Prensa.

35 Copia de teletipo urgente del Delegado Provincial al Subdirector General de los Servicios Informativos ( ${ }^{\circ}$ 770, emitido el 14 de febrero de 1973. Entre los intervinientes que se citan se encuentran: Antonio Elorza, con su ponencia: federalismo en España 1840-1868; Jorge Solé Tura: La I Republica y las clases sociales; así como Juan Trías: Federalismo en España y revolución burguesa. 


\section{La sombra de Salvador Allende}

En relación a los sucesos ocurridos en Chile con el golpe militar pinochetista que derroca a Allende, el caso que nos ocupa podría llegar a ser hasta divertido, si no fuera porque es veraz lo contando en estas líneas. De nuevo vamos a documentar una circular enviada mediante teletipo a las distintas Delegaciones en la que se advierte que en algún sector de la prensa comienza a «menudear» esquelas en memoria del Presidente Allende, donde "se aprovechan las trágicas circunstancias de su muerte para manifestar posiciones políticas o hacer adjetivaciones y alusiones también de claro matiz político totalmente lejanas a la motivación y finalidad propia de las esquelas" ${ }^{\prime 36}$. De esta forma -continúa diciendo la nota-, «personas y grupos interesados manipulan la figura y la memoria del fallecido Presidente chileno para abanderar propósitos y objetivos de clara significación política. Es manifiesto el propósito de ampararse en dichas inserciones seudo religiosas para hacer manifestaciones ideológicas de simpatía o descalificación política”. Ante esta situación manifiesta el Ministerio emite sus consignas: «los delegados provinciales deberán ponerse en contacto «urgentemente» con los directores de diarios y revistas de información general para significarle la postura oficial sobre la inserción de estas esquelas". Esta imagen de la dictadura quizás no deja de ser inaudita, por cuanto la estrategia que usan las fuerzas de oposición para homenajear al Presidente popular derrocado y asesinado. No obstante, la posición institucional por boca del representante ministerial quiere dejar claro que no existe "reparo a las esquelas que obedezcan a motivos religiosos o que tengan por objeto anunciar con anticipación la celebración de algún servicio fúnebre en memoria del fallecido». En cambio, no es considerado como procedente aquéllas que contengan intencionalidad claramente política, que tergiversen el sentido y la finalidad de las inserciones. Finalmente se añade que, «sería prudente» en tales casos, o en aquellos otros que ofrezcan alguna duda a los directores de medios, «sin perjuicio de exigir la autenticidad de identificación de los anunciantes, rechacen tales inserciones».

Al día siguiente y como continuación de la comentada circular hemos localizado entre el material que ha caído en nuestras manos un nuevo documento que continúa aportando hilo conductor al tema. A partir de las instrucciones anteriores se plantean «nuevas circunstancias» que hacen aconsejable «se pongan nuevamente» los Delegados en contacto con los directores de medios al objeto de facilitarles nuevas consideraciones: «tanto para prevenir un posible paso en falso como para orientar la labor de los directores en su quehacer informativo». La

36 Copia de circular ( $n^{\circ}$ 211) desde Madrid a los Delegados suscrita por Esteban de la Puente en calidad de Subdirector General de Régimen Jurídico de las empresas (es de entender de medios del Estado), registro de entrada 4460 de fecha 19 de septiembre de 1973. En el documento como suele ser costumbre figuran anotaciones manuscritas señalando la hora y el día de la comunicación verbal a personas concretas -generalmente directores o redactores jefes- de los diarios hispalenses. 
nueva nota se vuelve más contundente y concreta en sus directrices. Se ha constatado -dice- que los hechos que se anunciaban como aislados, responden a una «campaña organizada» destinada a promover en la prensa la inserción de esquelas en memoria del Presidente "fallecido", las cuales no tienen "otro objetivo que el de exteriorizar una simpatía y adhesión políticas, sin mención ni referencia alguna de carácter piadoso" (Puede observarse el matiz concreto en referencia a la presentación de la causa de su magnicidio, como sabemos, por defender la legitimidad de su régimen a manos del ejército golpista del país americano). Por ello, ya se emiten directrices para rechazarlas. Es más, «debe advertirse» ahora a los directores, sigue diciendo la circular, que la presencia de esquelas en sus medios en el sentido apuntado «podrán ser considerada como causa del secuestro de la publicación», debiendo por ello los periódicos adoptar las medidas oportunas para rechazar tales inserciones, a las que se consideran ahora «de carácter puramente político». En la medida que las esquelas anuncien algún servicio fúnebre de carácter religioso, es conveniente «su consulta previa» ante el peligro de que, el pretexto de la celebración de dichos actos sirvan de convocatoria «para manifestaciones políticas o desórdenes».

Sin duda la cuestión chilena, por cuanto paralela a la experiencia golpista que da origen al régimen de Franco, se convierte en una cuestión vital en doble sentido. Para la oposición, por cuanto desea ratificar la semejante significación de ambos casos, y para las altas instancias del régimen, a la hora de marcar distancias por todo lo contrario. De esta forma, y ante la existencia -según prosigue la circular-, de un Manifiesto firmado por personas de la vida intelectual española, se insta a los directores «a la no publicación ni referencia informativa» para con dicho texto. Su edición -sentencia la nota-, «determinará el secuestro del periódico». En esta misma línea, se apunta desde las autoridades del régimen la conveniencia de evitar en el tratamiento informativo de los acontecimientos chilenos «toda equiparación con el régimen político español, tanto en su contorno fundacional como actual». En suma: «se trata de cerrar el paso a toda maniobra política interesada en aprovechar los sucesos políticos chilenos para proyectarlos en nuestra realidad política». ${ }^{37}$

\section{Ejemplos de aperturas de expedientes}

Hemos logrado documentar tres teletipos enviados desde la Dirección General al Delegado relacionados con la apertura de expedientes al diario católico $E l$ Correo de Andalucía. Tienen en común la orden expresa de que la comunicación sólo sea verbal, y en los tres casos también dirigidos al Director del medio.

37 Copia de circular ( $n^{\circ}$ 212) desde Madrid a los Delegados suscrita por Esteban de la Puente en calidad de Subdirector General de Régimen Jurídico, registro de entrada 4464 de fecha 20 de septiembre de 1973. De nuevo se repite la conocida fórmula de las anotaciones al margen manuscrita en idéntico sentido. 
Igualmente en todos los supuestos se ruega se indique al Director General que instruye el expediente el cumplimiento de estas instrucciones y las manifestaciones del Director interesado sobre el asunto.

En el primero de los avisos se indica que se procede a la apertura de expediente por haber difundido en la pág. 15 del 19 de agosto de 1973 el texto titulado: El agua de San Juan de Aznalfarache no es potable. En el segundo de los casos, un nuevo expediente se justifica con haber difundido en la pág. 22 del número de 21 de agosto de 1973 una fotografía que no corresponde al pie de la misma. El tercero por divulgar en el número del 4 de agosto de 1973 la información titulada «los braceros de Gerena ante la eminente retirada de sus cartillas del SOE».38

\section{La aparición de la Junta Democrática en París.}

Los movimientos de la oposición aún en el extranjero, y su eco dentro de la geografía del Estado reciben un escrupuloso y atento tratamiento. Así, se informa desde el Ministerio que difundida por la Agencia Cifra se fecha en París la formación de una Junta Democrática anunciada en dicha capital por Santiago Carrillo para promover en España la constitución de un "pretendido Gobierno". Junto al Secretario General del Partido Comunista -se dice-, apareció únicamente D. Rafael Calvo Serrer, como «vocero adjunto» de dicha Junta. De ambos dirigentes se apunta, "se arrogan la representación de los demócratas españoles, insinuaron sin mencionar nombre alguno que cuentan con grupos partidarios dentro de España, aunque ninguno de ellos estuviera representado en la citada conferencia de prensa".

Se insta de los Delegados que indiquen, una vez más, a los directores de los periódicos que las posibles informaciones que, procedentes de corresponsales de París o por cualquier otra fuente, les lleguen sobre el tema citado, se acomoden a los términos de la misma, que en líneas generales puede servir de «módulo al tratamiento informativo, a fin de no secundar iniciativas políticas que, como ésta, contrarían abiertamente a nuestras leyes e instituciones". ${ }^{39}$

38 Teletipos del Director General de Prensa al delegado Provincial del Ministerio en Sevilla, las entrada en fecha 25 de octubre de 1973, registro de entrada núm. 5.100 hasta 5.102 respectivamente. No debe confundirse dichas siglas con el Partido Socialista Obrero Español, sino correspondientes a un sindicato vertical de la época.

39 Boletín para los delegados: 169, entrada 31 de julio de 1874, núm. 3643. 


\section{ANEXO
Informe cursado el 7 de diciembre de 1970 por la Delegación Provincial de Sevilla del Ministerio de Información y Turismo referente a las estructuras profesionales y económicas de las cabeceras sevillanas. ${ }^{40}$

$A B C$

Director: D. Joaquín Carlos López Lozano: persona muy conocida en Sevilla, en dónde dispone de evidente fuerza. Ex Presidente de la Diputación Provincial, cargo que ocupó mientras desempeñó el Gobierno Civil de Sevilla D. Hermenegildo Altozano Moraleda. Presidente en la actualidad de la Junta de Obras del Puerto y del Ateneo de Sevilla. Fue muchos años colaborador de Radio Sevilla como informador deportivo.

Subdirector: D. Francisco Luís Otero Nieto: Persona de evidente valía en la profesión y capacitado para el puesto que desempeña. De pluma fácil y con ideas.

Redactores: D. Manuel Olmedo Sánchez: redactor-jefe. Hijo del que fue director de este diario, D. Antonio Olmedo, periodista de Honor, fallecido hace años. Además de la crítica taurina, se ocupa de la de Arte, en la que gusta emplear un leguaje oscuro y enrevesado. Sin especial relieve profesional.

D. Nicolás Jesús Salas: Redactor Jefe, especialista en temas económicos. Hombre listo y con recursos, capaces quizás de suplir su preparación esquemática.

D. Javier Smith Carretero: Redactor Jefe, profesional de valía, pero de personalidad poco relevante. Tiene una bonita pluma, que dosifica mucho. D. Francisco Amores López: redactor de calle, de estilo populachero, aunque con éxito entre determinado sector de sus lectores. Hombre bullidor y simpático.

D. José Antonio Blázquez Cabrera: redactor deportivo sin especial relieve. D. Antonio Colón Vallecillo: sin especial relieve. D. José Luis Tasset Méndez: sin especial relieve.

D. Benigno González García: Teniente Coronel del ejército. Actualmente en la "segunda bis" de Estado Mayor. Fue colaborador de esta Delegación como inspector de Espectáculos. Fue también Ayudante del Capitán General de la Región. Esto le ha dado relaciones en distintos ambientes, de las que él gusta. Sin especial relieve profesional.

D. Remigio Ruiz Rodríguez: viejo periodista sevillano. Fue redactor jefe de Radio Nacional de España en Sevilla. Redactor de calle. De poco relieve profesional y personal.

D. Manuel Ferrand Bonilla: Escritor. Premio Planeta en 1968. Sus trabajos no se prodigan en el periódico, donde hizo un tiempo la crítica de TVE con evidente acierto a juicio de sus lectores. Persona muy preparada intelectualmente. Licenciado en Filosofía y Letras y dibujante. Colabora en "La Codorniz".

40 Dicho Informe -suscrito por el Delegado Santiago Corredoira Casares y calificado como "reservado"responde a su vez a una petición que, presumiblemente es dirigida a todas las provincias, y en donde el entonces Director General de Prensa en fecha 20 de octubre de 1970 solicita apreciaciones sobre el personal de los diarios. Más concretamente en lo referente a las publicaciones "más conflictivas", y a los redactores “con especial atención a los políticos". Igualmente se solicita un análisis de la estructura económica de la publicación y las conexiones, si las hubiese, "con personalidades políticas, religiosas o financieras". La continuidad de dichas apreciaciones son objeto de una nueva confirmación también por el mismo cauce "reservado", a través de escrito del Ministerio a la Delegación con fecha 31 de enero de 1973 (registro entrada 575). Esta vez el Delegado citado alega que las estructuras financieras y las condiciones de las empresas periodísticas son "prácticamente las mismas". Acompañando a su respuesta fechada el 10 de febrero, la relación nominal de cada una de las plantillas de los diarios hispalenses con el número del registro oficial de periodistas de cada uno de los profesionales, caso de poseerlo. 
D. Antonio Burgos Belinchón: Periodista procedente de la Escuela Oficial. Buen colaborador en el montaje de la Feria del Libro en Sevilla, a la que presta mucho calor en sus trabajador para ABC. Recientemente ha publicado un libro que acaba de salir a la calle.

D. Luis Conde Rivera: veterano periodista gallego, avecindado en Sevilla desde hace muchos años. Ha dirigido varios periódicos fuera de Sevilla. Colabora asiduamente en periódicos nacionales y extranjeros. Persona muy conocida en la profesión.

D. Juan Luis Manfredi Mayoral: joven periodista, recién salido de la Escuela. Sin referencias.

Colaboradores: D. Francisco Montero Galvache. Escritor muy conocido en Sevilla. Orador fácil, está considerado como "pregonero" constantes de festejos más o menos destacados (lo fue de la Semana Santa de Sevilla). En la actualidad quiere adquirir acciones de El Correo de Andalucía. Políticamente es persona que "juega a todo". Llegó a sonar hace años para el cargo de Delegado Provincial de Información y Turismo de Sevilla. Personalidad difícil. Poco clara.

D. Modesto Cañal: Director del Banco Santander en Sevilla. Se habló de él en su día para ocupar la Alcaldía de Sevilla. De la Hermandad de Marineros Voluntarios. Muy conocido en Sevilla.

D. Manuel Alonso Vicedo. Subdirector de Radio Sevilla, cuyo puesto ocupó tras varios años de brillante labor en Radio Popular de Sevilla. Hombre joven de evidente valía y destacada personalidad. Escribe sobre temas deportivos principalmente.

D. Julio Martínez de Velasco: Hombre de ingenio. Muy enterado de cuestiones teatrales. Quizás de las personas más competentes de la provincia en esta actividad. Redacta en ABC los "marginales" muy ingeniosamente.

Otros colaboradores: D. Domingo Manfredi Cano, D. José Montoto y González de la Hoyuela, D. Modesto Cañal Herrero-Valverde, D. Enrique Sánchez Pedrote, D. Santiago Montoto Sedas, D. Rafael Laffón, D. Juan de la Lastra y Terry, D. Jesús de las Cuevas, D. Manuel Barrios Macedo, D. Joaquín González Moreno, D. Darío Vecino, D. Tomás de Martín Barbadillo, D. Manuel Alonso Vicedo, D. Juan Infante-Galán, etc. Madrid.

Estructura económica: Su empresa es Prensa española S.A. idéntica que ABC de

\section{SEVILLA}

Director: D. Ignacio Arroyo y Martín de Eugenio, periodista que llegó a Sevilla de otras publicaciones de la prensa del movimiento. Persona cordial, dispuesto siempre a colaborar en todo aquello que se le pide.

Sudirector: D. Celestino Fernández Ortiz: buen periodista. Abogado en ejercicio. Ha desempeñado varios cargos en el municipio, el movimiento y sindicatos. Vicepresidente de la Asociación de la Prensa de Sevilla, que prácticamente dirige y Vocal de la Federación Nacional de Asociaciones de la Prensa. Hábil, inteligente e ingenioso. Actualmente dedica mayor tiempo que antes al ejercicio de la abogacía.

Redactores: D. Fausto Botello de las Heras, D. Mariano Martín Benito, D. José Angel Bonachera Pombo y D. Juan Manuel Borbujo de la Hera. Ninguno de ellos destaca especialmente en su actividad.

Colaboradores: D. Julián Calero Escobar: ex delegado Provincial de Sindicatos. Se distingue por sus artículos polémicos, especialmente frente a "El Correo de Andalucía". Inteligente y de estilo claro y elegante, ha salido numerosas veces en defensa de organizaciones e instituciones atacadas desde el matinal sevillano citado. Falangista. D. Angel Martín Sarmiento: sacerdote claretiano: como el anterior, polemista con "El Correo de Andalucía", en temas especialmente religiosos. Muy Hábil y moderado en el estilo, aunque punzante en el fondo de sus trabajos. 


\section{EL CORREO DE ANDALUCÍA}

Director: D. José María Javierre Ortas, sacerdote. Posee una buena pluma y gran preparación profesional y teológica. De gran simpatía personal, es, sin embargo, peligroso, tanto por su tendencia progresista democristiana, como por su especial manera de ser: de trato cordial y afable, pero que sabe ir a lo suyo, de cuyo camino no se aparta un milímetro. Se puede calificar como hombre de contrastes por su aparente ductilidad y su efectiva tenacidad, a los que le ayuda su especial habilidad e inteligencia evidente. No suele permanecer mucho tiempo en un puesto de trabajo. Fue propuesto para la dirección de El Correo de Andalucía por el Sr. Cardenal Arzobispo de Sevilla, D. José María Bueno Monreal.

Subdirector: D. José María Requena Barrera. Poeta y escritos de cierto relieve. Puede decirse que es más un hombre de letras que específicamente periodista. Sin tendencia política definida, no se destaca en este terreno en ningún sentido.

Redactor-Jefe: D. Juan José Gómez Martín. Veterano periodista sevillano, Director de "Hoja del Lunes". Profesional de la vieja escuela, enemigo de buscarse problemas. Es corresponsal en Sevilla de la Agencia "Logos". De la plantilla de "El Correo" en su anterior etapa y muy probablemente disconforme con la actual línea de su periódico.

Redactores: Ignacio García Ferreira, Antonio Rubio Sanz, Luis Joaquín Pedregal, Felipe García Pesquera y Manuel Murga de la Vega. Todos ellos de la antigua plantilla del periódico, de similares características al redactor-jefe.

Fernando Gómez Martínez "Gelán" (hijo). Delegado de Europa Press en Sevilla. Periodista literario y gráfico. Hombre joven, que dispone de grandes espacios en "El Correo", especialmente cuando se trata de temas deportivos.

Francisco Anglada Anglada: De la Escuela Oficial de Periodismo. Fue de la antigua plantilla del periódico, de la que cesó durante una temporada, para dedicarse totalmente al puesto de Jefe de Redacción de Radio Nacional de España de Sevilla, cesando también para ocupar, durante corta temporada, el puesto de Director de "Primera Plana" de Alicante. Posteriormente se reintegró a "El Correo". Hombre más moderado que algunos de los nuevos redactores, sin embargo no discrepa sustancialmente de su actual línea ideológica. Es redactor de cierre del periódico y profesional competente.

María Jesús González, sin referencia.

Auxiliares de redacción: Antonio Guerra Gil, Juan Holgado Mejías y José Guzmán Cruz. Ninguno de ellos está inscrito en el Registro Oficial de Periodistas y todos constituyen la base del trabajo de la nueva orientación del periódico: el equipo "de confianza" del Director. De plumas especialmente virulentas, se distinguen por sus continuos ataques más o menos velados al actual Régimen (sic) español, así como al Ayuntamiento de la Ciudad, Organización Sindical, etc. Por su trabajo en "El Correo" ha sido abierto expediente por intrusismo, por esta Delegación Provincial, a propuesta de la Asociación de la Prensa de Sevilla.

En la redacción, resta Concepción Cárceles Laborda, de la que no tenemos datos como auxiliar de redacción, José Fernández Rosas, sin significación especial.

Editorialistas: Existe en la actualidad el proyecto de crear un equipo de cinco personas dedicadas a esta actividad. Aún no está constituido. Ninguno de ellos será de la plantilla de redacción del periódico y se ocupará cada uno de temas específicos: Política, Economía, Religión, Social, etc. Hasta ahora, se han ocupado de los editoriales el propio Director y personas conocidas en Sevilla, como D. Pedro Luis Serrera, el profesor Navarrete, etc, todos ellos de clara tendencia democratacristiana.

Colaboradores: Varias personalidades sevillanas, de la misma tendencia. Aparte los citados como editorialistas, que también colaboran con su firma, no suelen tener colaboraciones fijos de forma habitual. El padre Chinarro Díaz, escribe habitualmente y 
con especial virulencia, la sección "Mundo Laboral", cuyas fuentes de información suelen ser las Comisiones Obreras.

Análisis de la estructura económica y breve historia de su desarrollo económico: El periódico es propiedad de la empresa "Prensa sevillana S.A.", que tiene su capital en acciones. Se fue a una ampliación del mismo a finales de 1966 ó principios de 1967, a cinco millones de pesetas, distribuidas, aproximadamente así: un 40\%, del total del capital social para Editorial Católica, S.A. de Madrid, si bien en los Estatutos se determina que sólo podrá ejercer el voto hasta un $25 \%$ de las acciones. Además, como accionistas importantes figuraban el Cardenal Arzobispo de Sevilla, D. Carlos Beca y las familias Rojas-Marcos y Pablo Romero, muy conocidas en Sevilla.

Posteriormente, en 1969, hubo una nueva ampliación del capital a quince millones de pesetas, suscribiendo las acciones correspondientes Editorial Católica, el Cardenal de Sevilla, que ha cedido parte de las suyas a personas de su confianza o línea política y los demás accionistas importantes cedieron las suyas o las suscribieron para venderlas posteriormente, entrando así en posesión de 2.790 acciones D. Rafael Oñós, su esposa, Da Mercedes Gutiérrez Arroyo y su hijo. Por otra parte, D. Alejandro Rojas-Marcos, ha cedido las que le correspondieron a numerosas personas de su línea política, pero en pequeños lotes, CON EL FIN DE CONTAR CON GRAN NÚMERO DE VOTOS (sic) en los consejos de accionistas, como así ha sido.

Conexiones con personalidades políticas, religiosas o financieras: Queda contestado este epígrafe en el anterior. Conviene añadir, sin embargo, la evidente vinculación actual del, periódico a las llamadas Comisiones Obreras, cuya política, de forma más o menos abierta, apoya "El Correo de Andalucía" desde sus columnas. Puede resumirse que, paradójicamente, el periódico tiene vinculaciones muy serias con destacados grupos capitalistas sevillanos y con otros grupos precisamente anti-capitalistas, pero ambos con el denominador común de su oposición más o menos abierta al actual Régimen español. 